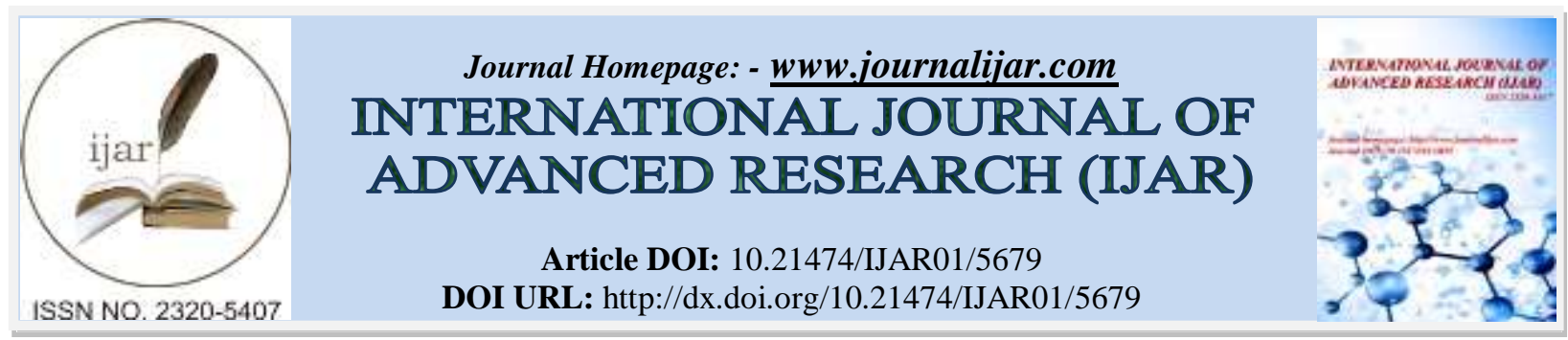

RESEARCH ARTICLE

\title{
GENDER BASED CONTRACEPTION AWARENESS AND PRACTICE: STUDY FROM A CENTRE IN NORTH-EAST INDIA.
}

\section{Dr. Manika Agarwal and Dr. Jupirika E Pyrbot.}

\section{Manuscript Info}

(..........................

Manuscript History

Received: 21 August 2017

Final Accepted: 23 September 2017

Published: October 2017

Key words:-

Gender , contraception , awareness, practice.

\section{Abstract}

Background: To prevent the growth of population contraception practices is important. Both male and females should take active participation.

Objective: To study the awareness regarding contraception in the male and female participants and the practices among the gender. To know the awareness regarding the gender based contraceptives available in the region of Shillong, North East India.

Method: It is a cross sectional study conducted during an awareness programme. Voluntary participants are asked to fill a questionnaire. Data in the form of age, parity, address, awareness regarding any method of contraception, practice of contraceptives. Result: A total of 140 participants, 90 male and 50 female. Both for male and female the most common age group was 26-30years. 26(28.89\%) male and $29(58 \%)$ female were in the age group 26-30 years. $86(95.56 \%)$ of males are aware of at least one type of contraceptive method. Female participant; 46(92\%) are aware of at least one type of contraception $(\mathrm{p}=0.385)$. In the male group $41(45.56 \%)$ practiced contraception and $38(76 \%)$ of the females practiced contraception, $\mathrm{P}=0.0005$. Among all the participants, $129(92.14 \%)$ are aware of condom. 87(62.14\%) of the participants are aware of the female method of birth spacing ie IUCD, Oral contraceptive pills and hormonal injectable.

Conclusion: Contraceptive practices were more among the female and awareness regarding the male method (condom) of contraceptive was more, though its practice is less. Thus there should be more awareness campaign regarding the various female methods available and other benefits of condom must be promoted in order to encourage its use.

Copy Right, IJAR, 2017,. All rights reserved.

\section{Introduction:-}

Population stabilization is a crucial topic of discussion in the past and at present. According to a report the world population will reach 8.5 billion people in $2030 .{ }^{(1)}$ Population on India is 1.324 billion, fertility rate is 2.45 and the population is expected to rise at a rate of $1.1 \%$ annually ${ }^{(1)}$. Hence it is important to stabilize the population growth. The GOI has proposed various programmes for controlling population growth like encouraging IUCD use, monetary benefits to users, etc. One of the programmes is the observation of Population Stabilization Fortnight. ${ }^{(2)}$

India is a country with diverse culture and ethnicity, with a male dominant society, therefore this study is conducted to see the gender based contraception awareness and practices from our region. Our study has been conducted 
during the "population stabilization fortnight" period wherein counseling regarding the various methods of

\begin{tabular}{|c|c|c|c|}
\hline & MALE & FEMALE & P-value \\
\hline AWARENESS & $86(95.56 \%)$ & $46(92 \%)$ & P=0.385 \\
\hline YES & $4(4.44 \%)$ & $4(8 \%)$ & \\
\hline
\end{tabular}

contraception along with services has been provided. During which voluntary participants are asked to fill a questionnaire.

\section{Methodology:-}

It is a cross sectional study conducted during $11^{\text {th }}$ July to $24^{\text {th }}$ July in NEIGRIHMS which is a tertiary centre in Shillong, Meghalaya. After taking informed consent, patients refusing to take part were excluded. Both male and female participants were interviewed separately. Among married couples only one participant was allowed to take part. A pre- structured questionnaire which included details like age, residence, number of children, awareness regarding various contraception methods specifically male type or female type of contraception and the type of contraception being practiced. After which the participants who have completed their family were motivated to adopt a method of sterilization.

Analysis of data was done using SSPS software. $(\mathrm{p}<0.05)$ is taken as statistically significant.

\section{Results:-}

Of the total number of participants interviewed $(n=140)$ male participants were 90 and female 50.

Both for male and female the most common age group was 26-30years. 26(28.89\%) male and 29(58\%) female were in the age group 26-30 years. Among the males $27(30 \%)$ has a single child and among the females $18(36 \%)$ has a single child. $15(16.67 \%)$ of the males have $\geq 3$ children and $12(24 \%)$ of the female participants have $\geq 3$ children (Table 1).

Among the males $86(95.56 \%)$ of them are aware of at least one type of contraceptive method and 4(4.44\%) are not aware. Female participant; 46(92\%) are aware of at least one type of contraception $(\mathrm{p}=0.385)($ Table:2). In the male group $41(45.56 \%$ ) practiced contraception and $54.44 \%$ did not practice any contraception method. Among the female participants $38(76 \%$ ) practiced contraception. $\mathrm{P}=0.0005$ (Table:3).

Among all the participants, 129(92.14\%) are aware of the male method of birth spacing ie condom. 87(62.14\%) of the participants are aware of the female method of birth spacing ie IUCD, Oral contraceptive pills and hormonal injectable.(Table 4).

Table-1:- age of the participants

\begin{tabular}{|c|c|c|}
\hline AGE(YEARS) & MALE & FEMALE \\
\hline $18-20$ & $1(1.1 \%)$ & $3(6 \%)$ \\
\hline $21-25$ & $19(21.1 \%)$ & $29(58 \%)$ \\
\hline $26-30$ & $26(28.89 \%)$ & $8(16 \%)$ \\
\hline $31-35$ & $21(23.33 \%)$ & $10(2 \%)$ \\
\hline
\end{tabular}

\begin{tabular}{|c|c|c|c|}
\hline & MALE & FEMALE & P-value \\
\hline AWARENESS & & & \\
\hline YES & $86(95.56 \%)$ & $46(92 \%)$ & P=0.385 \\
\hline NO & $4(4.44 \%)$ & $4(8 \%)$ & \\
\hline
\end{tabular}

Table 2:- Awareness of at least one method of contraception among male and female.

Table 3:- Contraceptive practices among male and female.

\begin{tabular}{|c|c|c|c|}
\hline PRACTICE & MALE* & FEMALE\# & P-value \\
\hline YES & $41(45.56 \%)$ & $38(76 \%)$ & P $=0.0005$ \\
\hline
\end{tabular}


(*male use of barrier contraceptive ie condom

\# Female use of OCP or hormonal Injectables or IUCD)

Table 4:- Awareness regarding male method and female method of contraceptive.

\begin{tabular}{|l|l|l|}
\hline Type of contraceptive awareness & $\begin{array}{l}\text { MALE CONTRACEPTIVE } \\
\text { (CONDOM) }\end{array}$ & FEMALE CONTRACEPTIVES \\
\hline YES & $129(92.14 \%)$ & $87(62.14 \%)$ \\
\hline NO & $11(7.86 \%)$ & $53(37.86 \%)$ \\
\hline
\end{tabular}

\section{Discussion:-}

For checking the exponential growth of population both male and female should take active part in the adoption of family planning. Temporary method for birth spacing and permanent method after family is completed. According to NFHS-4 the unmet need in India is $12.9 \%$. $^{(3)}$

The most common age group in our study was 26-30years which was similar to a study by Agarwal et al . ${ }^{(4)}$ Among the males $27(30 \%)$ has a single child and among the females $18(36 \%)$ has a single child. $15(16.67 \%)$ of the males have $\geq 3$ children and $12(24 \%)$ of the female participants have $\geq 3$ children

Awareness of atleast one method of contraception among the participants in our study (95.6\%) males and (92\%) among females is similar to other studies conducted in Indonesia ${ }^{(5)}$, and in India similar to a study in Sikkim ${ }^{(6)}$. Whereas in a study by Sunita et al there was $100 \%$ awareness of at least one type of contraception ${ }^{(7) \text {. }}$

The contraception use among women is $53.9 \%$ in India ${ }^{(3)}$. In our study we found that $38(76 \%)$ of the women were practicing at least one method of female contraception in the form of Oral contraceptive pill, Intrauterine contraceptive device, injectable contraception. In another study from Pakistan only $30.8 \%$ of women were practicing contraception ${ }^{(8)}$. This diversity could be possibility of influence and view of religion. In India the condom usage is $5.6 \%$ according to NFHS-4(3). In our study 41(45.56\%) of the males are using condom as a method of contraception which is higher as compared to the national statistics. In another study from India $59.7 \%$ of the couple was practicing condom as a method of contraception ${ }^{(7) .}$ In our study it is seen that the contraception practice among female is higher than that of male $(\mathrm{p}<0.05)$. Probably men's attitudes on gender equality play a significant role in use of contraception ${ }^{(9)}$. The reported problems related to not using condom include not accepted by sexual partner, perceived ineffectiveness, less comfort, lack of sexual satisfaction with condoms, husband's alcohol use, depression, anxiety, and not available at that instant ${ }^{(10)}$.

$129(92.14 \%)$ of the participants were aware of the male method of contraception (ie condom) and $87(62.14 \%)$ of the participants were aware of the female method of contraception. Thus showing a higher awareness about condom which is similar to a study by Sood $\mathrm{A}^{(11)} 95 \%$.

\section{Conclusion:-}

In order to curb to exponential growth of population use of contraceptive methods has to be popularised. Both male and female should take active participation. Additional benefits of male barrier contraceptive should be popularised and males should be encouraged for its use. Various methods of female contraceptives should be promoted more through media, print, etc in this part of the region in the local vernacular language.

\section{Bibliography:-}

1. Elaboration of data by United Nations, Department of Economic and Social Affairs, Population Division. World.

2. National Population Policy, Government of India Ministry of Health and family Welfare, 11-December-2015.

3. National Family Health Survey - 4, 2015 -16, Ministry of Health and Family Welfare, Government of India.

4. Mukta Agarwal, Sutapan Samanta, Divendu Bhusan, Monika Anant. Assessing knowledge, attitude, and practice of contraception: a cross- sectional study among patients in a semi-urban tertiary hospital. Int $\mathbf{J}$ Reprod Contracept Obstet Gynecol. 2017 Feb;6(2):720-724. 
5. Budi I Santoso, Raymond Surya. Knowledge, Attitude, and Practice of Contraception among Pregnant Women in Ende District, East Nusa Tenggara, Indonesia. Journal of South Asian Federation of Obstetrics and Gynaecology, April-June 2017;9(2):110-11

6. Renjhen et al. Knowledge of contraception among college student. J Turkish-German Gynecol Assoc 2010; 11: $78-81$

7. Sunita Ghike et al. Awareness and Contraception Practices among women-An Indian Rural Experience, JSFAOG, January-April 2010;2(1):19-21.

8. Musarrat jabeen, fouzia gul, farmanullah wazir, nargis javed. Knowledge, attitude and practices of contraception in women of reproductive age, Gomal Journal of Medical Sciences July-December 2011, Vol. 9, No. 2

9. Anurag Mishra,et alMen's attitudes on gender equality and their contraceptive use in Uttar Pradesh India,Reproductive Health,2014;11:41

10. Vigneshwaran E, Padmanabha Reddy Y, Devanna N, Jaffar Sadiq M, Manoj Kumar B, Rubia S, et al. Evaluation of barriers in condom use - a cross sectional survey. Int $\mathrm{J}$ Res Pharmaceutical Biomed Sci. 2011;2:510-5.

11. Aditya Sood,et al . Vasectomy: a study of attitudes, beliefs, knowledge and practices among literate men in Punjab, India Int J Reprod Contracept Obstet Gynecol. 2014 Jun;3(2):418-423 